\title{
ARQUETAS NOBILIARIAS \\ DE LA SEGUNDA MITAD DEL SIGLO XVI PARA EL SERVICIO DE LA IGLESIA*
}

\author{
POR \\ Carmen Heredia Moreno \\ Universidad de Alcalá
}

En este artículo se analizan varias arquetas de plata de la segunda mitad del siglo XVI que pertenecieron a destacados miembros de la nobleza y el clero y que hoy se guardan en diferentes iglesias castellanas. Además de su forma y de su posible origen, se presta atención a su programa iconográfico y se valora el importante papel que estos objetos profanos desempeñaron en la liturgia católica en el contexto de la Iglesia española de la Contrarreforma.

Palabras clave: Platería; Arquetas; Donaciones; Nobleza; Siglo XVI.

\section{SMALL 16TH-CENTURY SILVER CHESTS OF THE NOBILITY FOR THE SERVICE OF THE CHURCH}

In this article several silver caskets dating from the second half of $16^{\text {th }}$ century are analysed. They belonged to distinguished members of the nobility and today are located in various Castilian churches. Their shape, origin and iconography are studied as well as the important role that these profane objects played in the Catholic liturgy of the Counter-Reformation Spanish Church.

Key words: Silverwork; Caskets; Donations; Nobility; $16^{\text {th }}$ century.

El arte como instrumento de poder o como expresión de los contactos y del profundo entendimiento entre los poderes civiles y religiosos constituye uno de los capítulos más atractivos de la historia de la Edad Moderna y refleja los estrechos vínculos existentes entre lo sagrado y lo profano. Ejemplos elocuentes nos brinda el Renacimiento italiano desde el Quattrocento en que los pintores Gentile de Fabriano o Benozzo Gozzoli llegaron a representar a las familias patricias florentinas de los Strozzi o los Médici en los cortejos de los Reyes Magos casi al mismo nivel que las figuras sagradas, en una suerte de retrato colectivo donde lo religioso se

* Este trabajo se inserta en el Proyecto de Investigación de I+D "Patronazgo nobiliario en la Monarquía de los Austrias. Arte y política entre la Corte Real y las cortes periféricas", código de referencia HAR2008-02349/ARTE. 
llevaba hasta el límite de lo profano, o viceversa, para mayor gloria de tan ilustres apellidos ${ }^{1}$. De parecida forma, los personajes nobles se introducen y participan en las fiestas religiosas europeas y españolas del quinientos, reflejando los intereses comunes de los distintos poderes públicos ${ }^{2}$.

En el ámbito de la platería, esta situación queda bien patente en los relieves de las arquetas de San Eugenio (1565) y de santa Leocadia (1580) donde Francisco Merino reprodujo las fiestas de recepción de las reliquias en Toledo con los miembros de la familia real entre un nutrido acompañamiento de nobles y eclesiásticos desfilando en el cortejo ${ }^{3}$. Estos ideales y sentimientos comunes se reflejan también a través de numerosos ejemplos de piezas civiles de plata labrada que pasaron a engrosar los ajuares litúrgicos de las iglesias españolas gracias a las donaciones realizadas por personajes laicos o religiosos y que, con ligeros cambios o incluso a veces sin necesidad de alterarlas en absoluto, llegaron a utilizarse con una clara funcionalidad religiosa a pesar de su procedencia del ámbito profano ${ }^{4}$.

En este contexto, analizamos ahora cinco arquetas de madera recubiertas de chapas de plata con molduras de ébano que se localizan en distintas instituciones de las antiguas archidiócesis de Toledo y de Valladolid y que, además de sus materiales y de su cronología parecida dentro de la segunda mitad del siglo XVI, tienen en común su forma, dimensiones y rasgos estilísticos. Tales semejazas permiten suponer, en principio, que se labraron en centros plateros próximos o, incluso, en un mismo taller. Además, aunque hasta fechas muy recientes todas han desempeñado una función litúrgica muy definida, como relicarios o como arquetas eucarísticas, al menos tres de ellas están decoradas con temas mitológicos o de contenido profano, por lo que puede asegurarse que proceden del ámbito doméstico y que se confeccionaron como piezas civiles para servir en el ajuar de viviendas nobiliarias 5 . Por lo tanto, la razón de su presencia en los tesoros de las respectivas iglesias donde hoy se encuentran hay que buscarla en las donaciones efectuadas por sus primitivos propietarios, que debieron ser destacados miembros de la nobleza o del clero. Todas las piezas han sido objeto de algún estudio y algunas se han relacionado con Italia, pero su conocimiento es todavía incompleto y ciertos datos carecen de respaldo documental sólido. Por todo ello, nuestro objetivo consistirá en revisar el actual estado de la cuestión para profundizar en el análisis de sus formas, iconografía y fuentes, y para tratar de descubrir su origen.

La arqueta del monasterio de las Bernardas de Alcalá se utilizó para la reserva eucarística del Jueves Santo hasta hace unos años y se exhibió por primera vez en la exposición celebrada en el claustro de la iglesia Magistral complutense en el 1926 (fig. 1) ${ }^{6}$. Después, por una serie de acontecimientos fortuitos relacionados con la Guerra Civil de 19367, albergó los restos del

\footnotetext{
1 Argan, G. C., Renacimiento y Barroco I. De Gioto a Leonardo da Vinci, Madrid, 1987, pp. 122-24 y 246-247.

2 Bastaría echar un vistazo al clásico volumen de AlEnda y Mira, J., Relaciones de solemnidades y fiestas públicas de España, Madrid, 1903.

${ }^{3}$ Están reproducidas en AlcoleA, S., Artes decorativas en la España cristiana (siglos XI-XIX), Madrid, 1975, figs. 243-244.

${ }^{4}$ Heredia Moreno, C., "De lo profano a lo sagrado. La platería civil en las catedrales españolas", en J. Rivas Carmona (coord.), Estudios de platería. San Eloy, 2009, Murcia, 2009, pp. 265-286.

${ }_{5}$ Numerosos ejemplos confirman el cambio de uso de muchas piezas de plata de carácter civil, como se detalla en Heredia Moreno, C., "De lo profano a lo sagrado...", op. cit.

${ }^{6}$ La mencionó por primera vez en torno a 1926, Tormo, E, Alcalá de Henares, Madrid, s/a, p. 70 . Medidas: $60 \times 40$ $\mathrm{cm}$ de base y 45 de alto. Carece de marcas.

7 Álvarez Lopera, J., La politica de bienes culturales del Gobierno Republicano durante la Guerra Civil española, Madrid, 1980, vol. II, pp. 88-91, recoge que, tras los episodios bochornosos que ocurrieron en Alcalá de Henares en relación con el patrimonio artístico, Lacarra y Juliá lograron evacuar a Madrid en 1937 un total de 350 cuadros, 593 objetos y 16 muebles. Más reciente, Lledó ColladA, P., Alcalá en Guerra, Alcalá de Henares, 1999.
} 


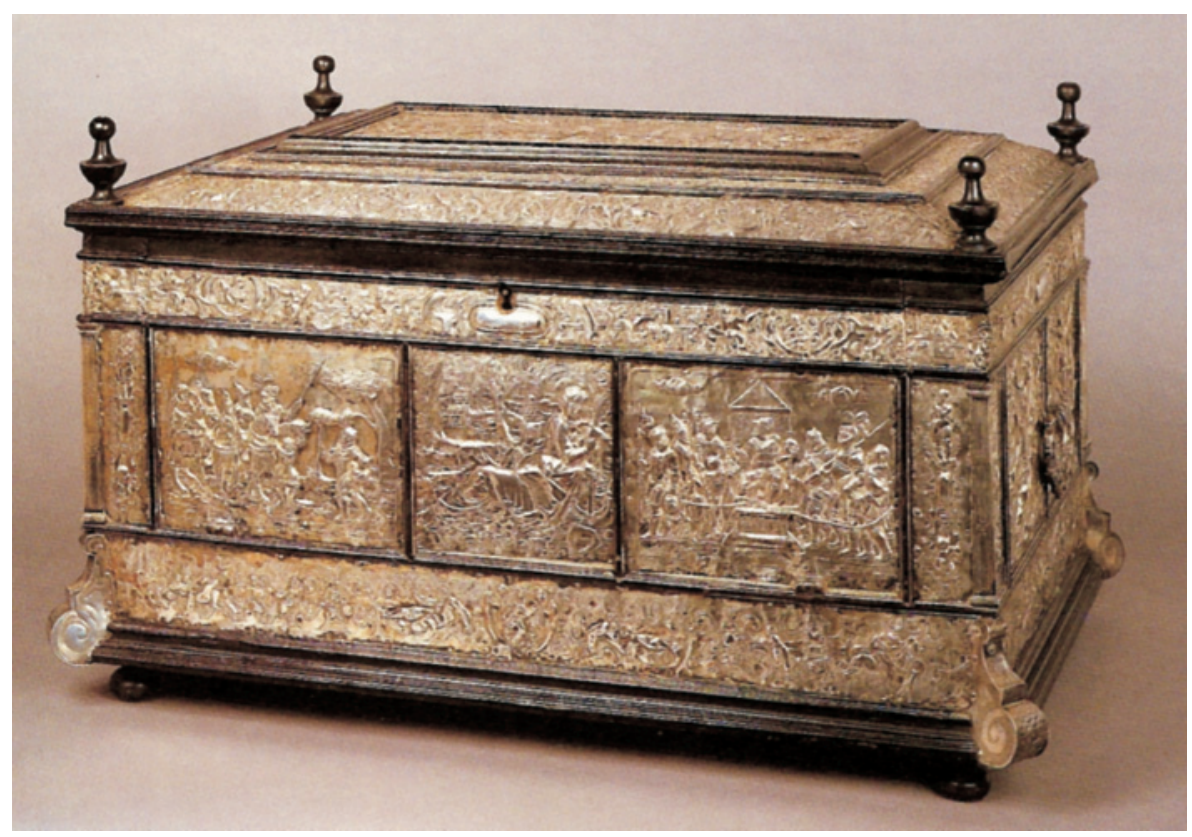

Fig. 1. Arqueta de las Bernardas. Alcalá de Henares.

cardenal Cisneros durante cuatro décadas ${ }^{8}$. Se conserva el acta de la Junta de Incautación, fechada en 14 de marzo de 1937, en cuya entrada número 4 José María Lacarra y Vidal Arroyo anotaron "Un arca de ébano y plata del siglo XVII (Bernardas)" . Es evidente que, a pesar de adjudicarle una cronología equivocada, el apunte se refiere a la arqueta de las victorias de Carlos V. También se conserva una carta autógrafa del profesor Lacarra que da cuenta del depósito de los restos del prelado en el arca de las Bernardas en el mismo mes de marzo de 1937 "por darles una colocación decorosa", así como el acta de recepción y de inhumación de las reliquias en la Magistral complutense, que tuvo lugar el once de noviembre de 1977, junto con la orden de devolver la arqueta de plata a su legítimo dueño que era el convento de las Bernardas de Alcalá de Henares ${ }^{10}$.

Sin embargo, a pesar de haberse utilizado durante varios siglos para el servicio de la iglesia del monasterio complutense, su superficie va cubierta por un complejo programa iconográfico de carácter alegórico profano, con cuatro relieves sobre las victorias del emperador Carlos V más los de las personificaciones de las siete Virtudes -Teologales y Cardinales- y otras figuras alegóricas, que se toma como espejo y modelo a seguir para su hijo Felipe II (fig. 2). Sus fuentes iconográficas proceden de estampas europeas diversas, sobre todo de la serie publicada por Marteen van Heemskerck (1556) y Cornelis Cort (1561) pero su autoría la atribuimos al platero real

\footnotetext{
${ }^{8}$ Reymundo Tornero, A., Datos históricos de la ciudad de Alcalá de Henares, Alcalá de Henares, 1951, p. 398, indicó que había servido como arqueta eucarística y que desde la Guerra Civil albergaba los restos del cardenal Cisneros.

${ }^{9}$ Instituto de Patrimonio Cultural Español (IPCE), Leg. 33, Acta n. ${ }^{\circ}$ 1, Junta de incautación y Protección del Patrimonio. 14 de marzo de 1937. José M. a Lacarra y Vidal Arroyo, personados en el ayuntamiento. "4.- Arca de ébano y plata. S. XVII (Bernardas)".

${ }^{10}$ Marchamalo Sánchez, A. y M. Marchamalo Main, El sepulcro del Cardenal Cisneros, Alcalá de Henares, 1985, pp. 239-241 y 254, apéndices XIV y XVII, transcriben los textos completos.
} 


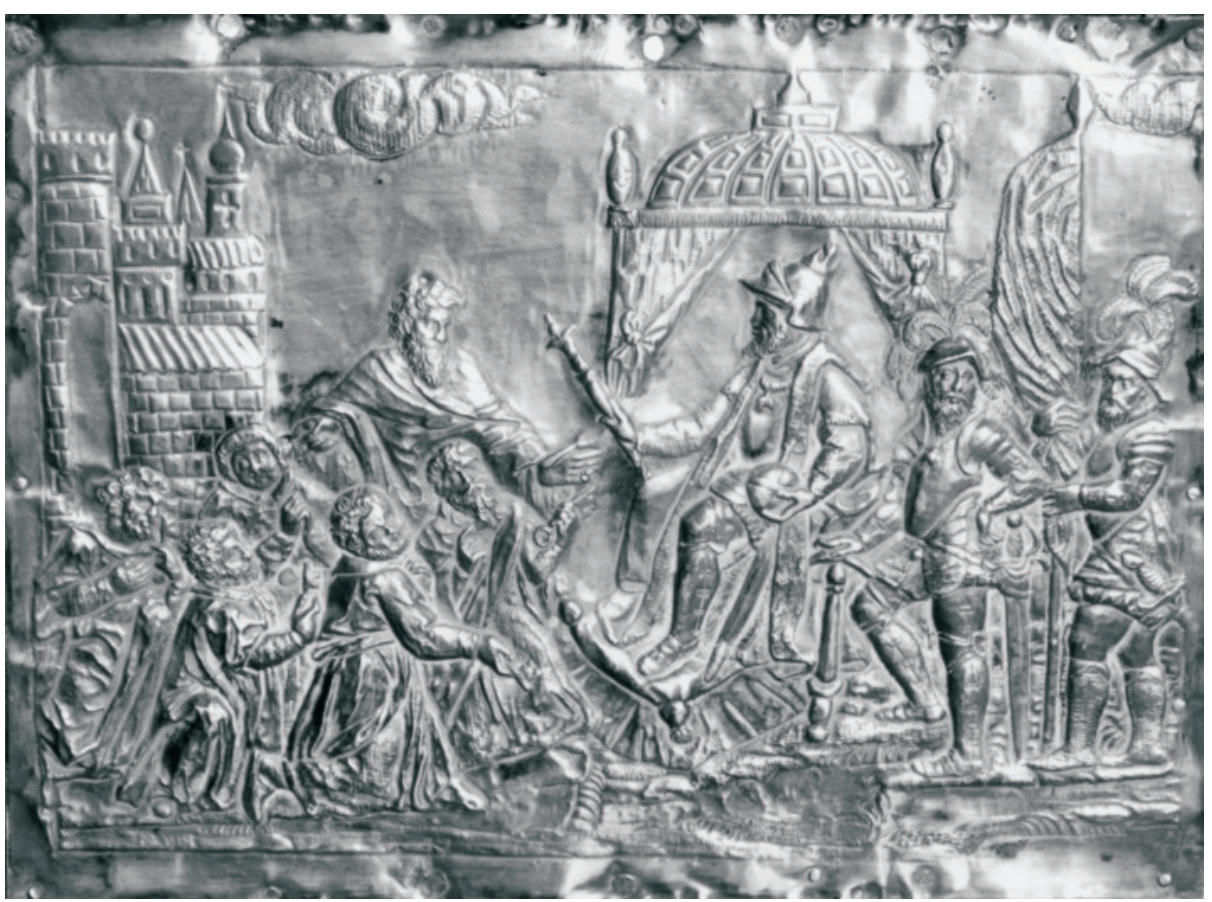

Fig. 2. Arqueta de las Bernardas. Las ciudades de la Liga se someten a Carlos V.

Manuel Correa o a otro artífice del entorno de la corte madrileña ${ }^{11}$, ya que consta por la documentación que este maestro acompañó al príncipe Felipe en sus viajes por Europa y que, entre otras obras, realizó "unas arcas de plata labradas a cincel adornadas con medallas de figuras alegóricas"12. La donación al convento alcalaíno la efectuó su fundador el cardenal arzobispo de Toledo don Bernardo de Sandoval y Rojas en el año 1626, junto con un nutrido lote de plata labrada para el servicio del culto ${ }^{13}$. Don Bernardo era tío del duque de Lerma y valido de Felipe III, don Francisco de Sandoval y Rojas, y su familia había mantenido estrecha relación con la monarquía desde los tiempos del Emperador Carlos, lo que explica la temática de la arqueta y plantea la posibilidad de que ésta hubiese sido un regalo real a algún miembro de la familia Lerma, el propio arzobispo inclusive ${ }^{14}$.

Respecto a la arqueta de la parroquia de Fuensalida, Rosino Pardo nos informa que la regaló en 1596 el IV conde de este título, don Pedro López de Ayala, con el deseo expreso de que sir-

${ }^{11}$ La identificación de los relieves con escenas de la vida de Carlos V se recoge en la carta del sr. Lacarra que se menciona en la nota 9. Castillo Oreja, M. A., Clausuras de Alcalá, Alcalá de Henares, 1983, p. 33, localizó las fuentes iconográficas de cuatro relieves en la serie de estampas de Marteen van Heemskerck sobre las victorias de Carlos V, editada en el año 1556. Su análisis y significado completo en Heredia Moreno, C. y A. López Yarto, "Los triunfos del Emperador en las artes del metal", en El arte en las cortes de Carlos V y de Felipe II, Madrid, 1999, pp. 363-375

12 AGS., CSR, leg. 36, fol. 5, recogido por CheCa Cremades, F., Felipe II Mecenas de las Artes, Madrid, 1992, pp. 29 y 470.

13 Heredia Moreno, C., "Donaciones de plata labrada del cardenal arzobispo de Toledo don Bernardo de Sandoval y Rojas", en Estudios de platería, San Eloy, 2003, Murcia, 2003, p. 275.

${ }^{14}$ Una semblanza sobre los títulos y la trayectoria del arzobispo en Heredia Moreno, C., "Donaciones de plata labrada...", op. cit., pp. 261 y ss. 


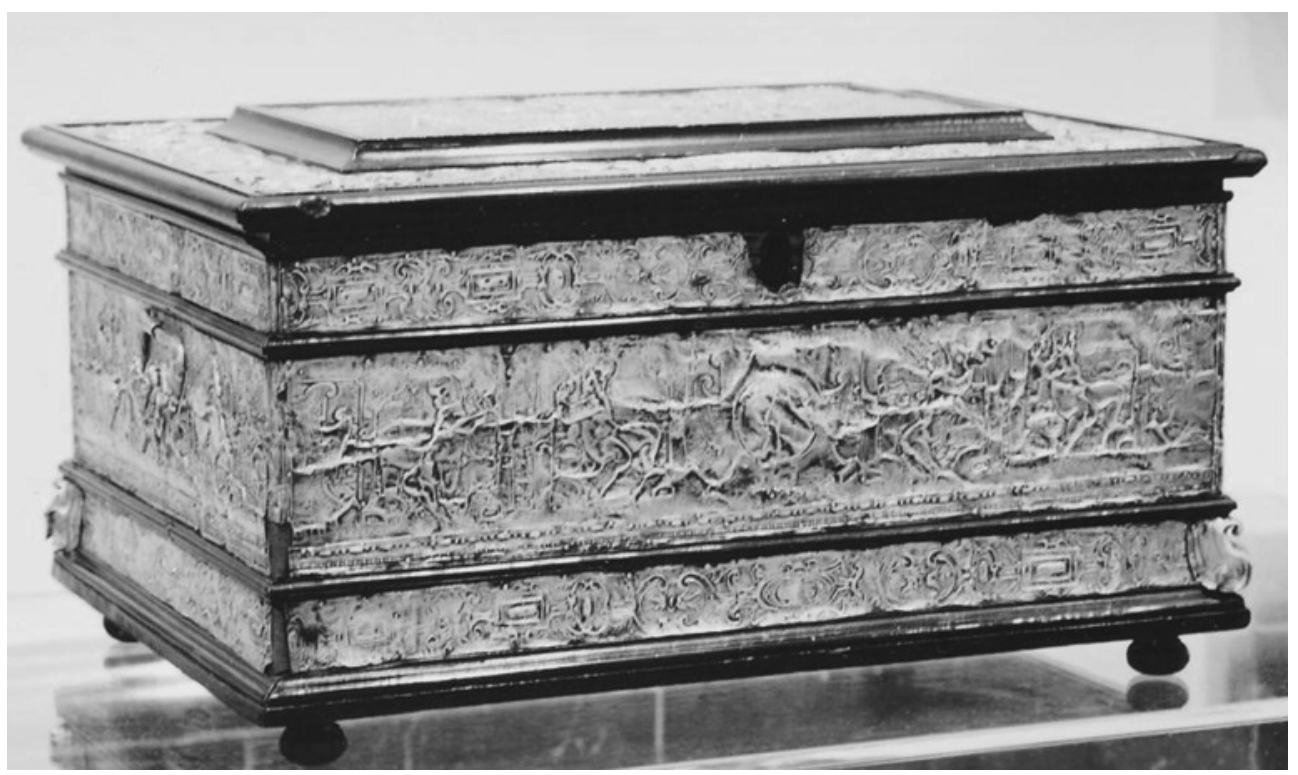

Fig. 3. Arqueta de la parroquia de Fuensalida.

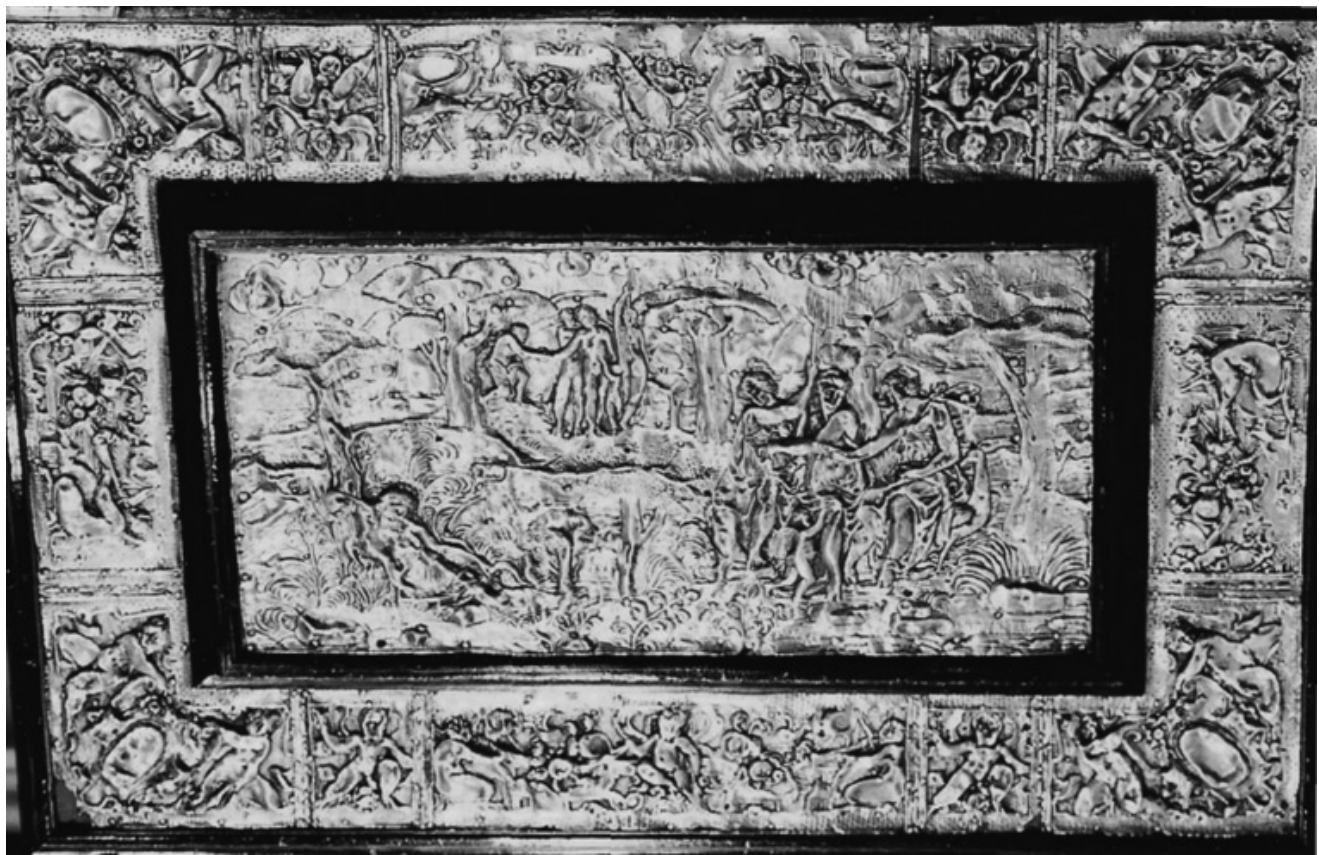

Fig. 4. Arqueta de la parroquia de Fuensalida. El juicio de Paris. 
viese para reservar el Santísimo (fig. 3) ${ }^{15}$. Don Pedro fue compañero, amigo y servidor de Felipe II, lo acompañó en todos sus viajes y estuvo luchando en la batalla de San Quintín ${ }^{16}$. Esta misma autora elogia la calidad de la obra de plata e identifica y describe sus relieves. El Juicio de Paris, en la cubierta, y franjas con niños sujetando cuernos de la abundancia y óvalos entre cintas, flores y motivos geométricos, en los frentes y en los costados (fig. 4). Martínez Burgos añade que el conde fue Comendador de Castilla, miembro del Consejo de Guerra y mayordomo mayor del monarca, al que acompañó a Inglaterra. Fue enterrado en la iglesia del convento dominico de San Pedro Mártir de Toledo, en donde mandó labrar una sepultura con los bultos orantes de él y de su esposa Magdalena Cárdenas en mármol de Carrara, de factura genovesa próxima al taller de los Carlone ${ }^{17}$. Respecto a la arqueta, Martínez Burgos afirma que "fue comprada en alguno de los muchos viajes a Italia y queda como ejemplo de un gusto claramente orientado hacia el arte italiano"18. También comenta lo inapropiado del tema mitológico en un contexto religioso eucarístico, razón por la cual se procedería a censurar los desnudos, machacando y hundiendo los relieves correspondientes, para disimular la falta de decoro.

La lectura y análisis del testamento del conde proporciona ahora otras noticias biográficas, a saber, que "Dicho Señor empleo 64 años en servicio de las Magestades de Phelipe 2." y 3.", acompañando a aquel monarca diferentes veces a Aragón, Cathaluña, Valencia, Córdova y lebantamiento de los moros de Granada y asimismo a tomar posession de sus Reynos de Portugal; a Inglaterra quando se fue a casar; a Flandes y todas las guerras que dicha Magestad tubo en Francia y Alemania. Fue embiado a Viena a grandes negocios y a visitar en su nombre a el emperador Maximiliano y consolarlo de la muerte de su padre el Emperador Fernando, dejando a su disposición lo que conviniese hacer en la procedencia de España y Francia y negocios en Genova [...], haviendo estado dos o tres veces en dichas provincias y en las guerras de San Quintín" 19 .

Es decir, según la documentación, el IV Conde de Fuensalida actuaba como hombre de confianza y como embajador del monarca en las cortes europeas, por lo que cabe la posibilidad de que comprase o recibiese la arqueta como regalo diplomático en alguno de sus viajes a Génova ${ }^{20}$. Sin embargo, los conflictos bélicos en los que se vio involucrado no nos parecen las circunstancias más propicias para entretenerse en estos asuntos de carácter suntuario. En la escritura de donación, fechada en 23 de agosto de 1596, no se indica el origen de la pieza, aunque sí se mencionan sus dimensiones aproximadas, sus materiales y el uso y lugar a los que iba destinada: "Manda y dona y presenta al Santísimo Sacramento de la eucaristía que está y se celebra en la yglesia parrochial de Señor San Juan Vautista desta villa [...] una arca de plata como de tres quartas de largo y media vara en ancho poco más o menos, con su cerradura y llave y la llave dorada y con su funda [...] y se entregue al licenciado Antonio de Rroxa, cura de la dicha yglesia [...] donde esté en buena guarda para el servicio y ornato del dicho Santísimo Sacramento y para le poner y enzerrar el Jueves Santo y los demás días y tiempos que sea ne-

15 Rosino Pardo, M. L., Historia de Fuensalida, Toledo, 1993, pp. 89-91, cita la carta de donación, que no recoge, en cambio, LeÓn Tello, P., Archivo de los duques de Frías, III, Madrid, 1973, pp. 261-266, entre la documentación del IV Conde de Fuensalida.

16 Rosino Pardo, M. L., Historia de..., p. 15.

17 Martínez Burgos García, P., "Arqueta de 'El juicio de Paris"”, en Felipe II. Un monarca y su época, un príncipe del Renacimiento, Madrid, 1998, pp. 475-477. Véase también Estella Marcos, M., "Artistas de los sepulcros de los Marqueses de Aguilar y procedencia de los Condes de Fuensalida, en Estudios de Arte: Homenaje al Profesor Martín González, pp. 327-335.

18 Martínez Burgos García, P., "Arqueta”, ob. cit.

19 España. Ministerio de Cultura. Sección Nobleza del AHN, Frías, C. 841, D. 36-46.

${ }^{20}$ Existe una amplia bibliografía sobre el papel que desempeñaron los regalos en las relaciones diplomáticas europeas del siglo XVI. 
cesario y que siempre la dicha arca permanezca sin la sacar de la dicha yglesia, de lo qual tengan particular cuydado..."21. El documento no describe tampoco el contenido de los relieves, quizás por lo inadecuado de la mitología y el desnudo para servir en la liturgia eucarística. Sin embargo, su mutilación indica que tales temas no pasaron desapercibidos a los responsables eclesiásticos.

Además el juicio de Paris es muy poco frecuente en las artes figurativas hispanas contemporáneas. Un caso excepcional encontramos en la pintura de Juan de Juanes que hoy se guarda en el museo italiano de Udine y que tiene composición distinta ${ }^{22}$. Sin embargo en Alcalá de Henares existió otra pintura con el mismo tema, que Hernando de Ávila, "maestro de pintura de la santa iglesia de Toledo", tasó en seis ducados en 1580. Esta obra se encontraba entre las figuras y jeroglíficos que el pintor alcalaíno Juan de Cerecedo había hecho para decorar los patios del Colegio Mayor de la Universidad complutense con motivo de la visita que el cardenal archiduque Alberto iba a realizar con su tío Felipe II para asistir al acto de su imposición del grado de licenciado en $\operatorname{Artes}^{23}$. La fiesta se suspendió, pero las pinturas se conservaban todavía en 1587, fecha en que fueron retasadas por Juan de Cleves. Ignoramos cómo era su composición, pero este mismo asunto es el que se reproduce en la arqueta de Fuensalida y en la de la iglesia Magistral de Alcalá de Henares, repitiéndose de manera literal en ambas piezas de plata el pasaje mitológico desdoblado en dos escenas, hasta tal punto que cabría considerar la mano de un mismo artífice o, al menos, el mismo círculo de plateros.

La de la Magistral fue descubierta de forma casual durante la revisión de los restos de los Santos Niños Justo y Pastor, efectuada por el obispado de Alcalá con motivo de la celebración del jubileo en el año 2005, en el interior de la de los hermanos Zurreño, donde se guardaban las reliquias de los mártires desde comienzos del siglo XVIII (fig. 5) ${ }^{24}$. La identidad de sus relieves mitológicos con los de Fuensalida me indujo a pensar entonces que se trataba también de una obra italiana, al tiempo que logré identificar una de las escenas del Juicio de Paris con la conocida estampa de Marco Antonio Raimondi según la pintura desaparecida de Rafael (fig. 6) ${ }^{25}$.

Por lo que concierne a su llegada a la iglesia de Alcalá, está documentado que la arqueta pertenecía a esta institución complutense desde antes de 1702 ya que, cuando en esta fecha se procedió al traslado de las restos de los mártires a la de los Zurreño, el cabildo de la Magistral "resolvió que las Sagradas Reliquias se pusiesen en otra arquita que estuviese dentro de la nueva y respecto de tenerla esta Santa Iglesia muy decente, con planchas de plata y perfiles de ébano, en ella se colocasen [...] y se halló que venía muy bien, quitándose algo de las puntas de la tapa..."26.

21 Frías, C. 850, D. 15, Sección Nobleza del Archivo Histórico Nacional. Las tres cuartas de largo por media vara de ancho equivaldrían a unos $62 \mathrm{~cm}$ de largo $\times 42$ de ancho, frente a los $53 \times 38 \mathrm{~cm}$ que indica Rosino Pardo, pero en el documento las medidas son aproximadas "poco más o menos".

${ }^{22}$ Fue identificada por PÉREz SÁnchez, A. E., "Juan de Juanes en su centenario", Archivo de Arte Valenciano, I, 1979, pp. 5-16. Después se exhibió en la exposición organizada por DoméNECH, F. B., Juan de Joanes. Una nueva visión del artista y su obra, Valencia, 2000, p. 124, núm. 31.

23 GonzÁlez Ramos, R., "La visita del archiduque cardenal Alberto de Austria a la universidad de Alcalá de Henares y la obra efímero-emblemática del pintor Juan de Cerecedo", Boletín del Museo e Instituto Camón Aznar, núm. XC, 2003, pp. 77-98.

${ }^{24}$ Se analizó en Heredia Moreno, C., "Sociedad, devoción y donaciones artísticas. Los SS. NN. Justo y Pastor de Alcalá de Henares”, en M. Cabañas Bravo, A. López-Yarto Elizalde y W. Rincón García (Coor.), Arte, poder y sociedad en la España de los siglos XV al XX, Madrid, 2008, pp. 648-650.

25 The Illustrated Bartsch, Marcantonio Raimondi, 26, vol. 14 (part 1), New York, 1978, p. 242.

26 "Acta del traslado de las reliquias de Justo y Pastor al arca de plata labrada por los hermanos Zureño", transcrita por Fernández Díaz, J., Los Mártires de Alcalá, Alcalá de Henares, 1920, pp. 170-177. Está recogida por MARCHAmalo Sánchez, A. y Marchamalo Main, M., La iglesia Magistral de Alcalá de Henares, Alcalá de Henares, 1990, Apéndice n. ${ }^{\circ}$ XXXI. 


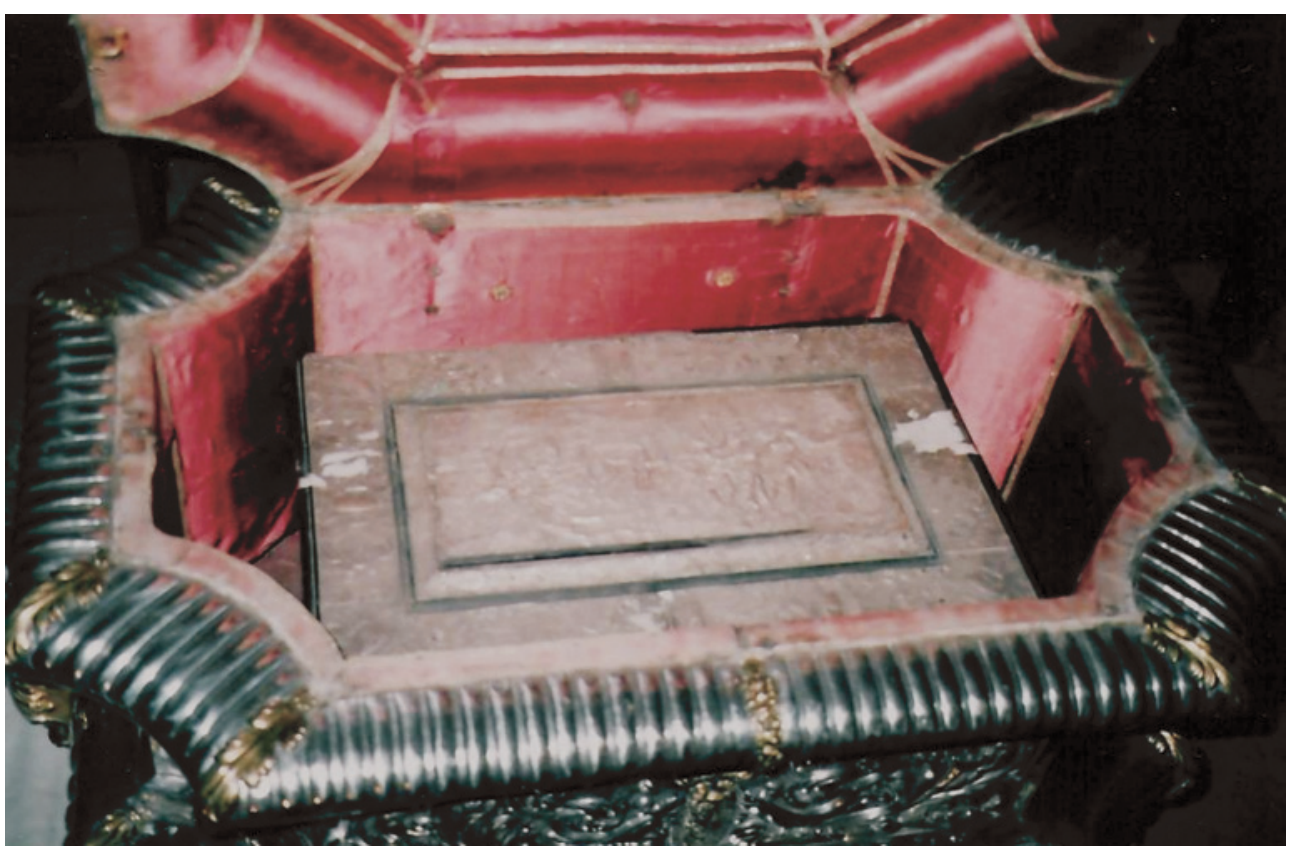

Fig. 5. Arqueta de la Magistral (Foto Ángela Flores).

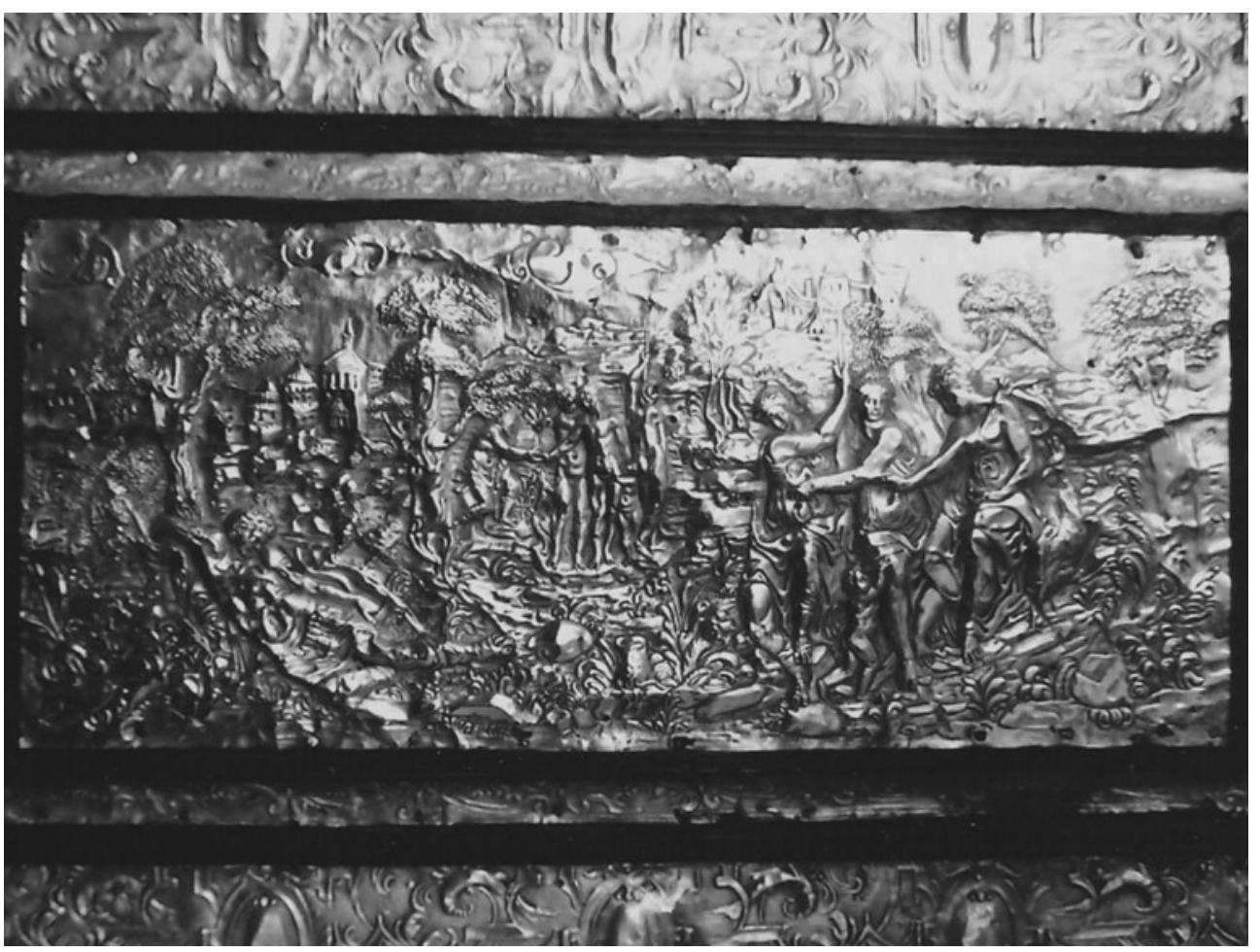

Fig. 6. Arqueta de la Magistral (Foto Ángela Flores). El Juicio de Paris. 
En el año 2003 relacioné su donación con el cardenal y arzobispo de Toledo don Bernardo de Sandoval y Rojas, que tanto favoreció a la villa universitaria durante el tiempo que estuvo al frente de la archidiócesis ${ }^{27}$. Sin embargo, ante la falta de documentos y en el terreno de la hipótesis, no pueden descartarse a otros posibles donantes, como al arzobispo García de Loaysa que, a su muerte acaecida en 1599, legó a la Magistral "Mucha plata para el servicio del altar..." o a algún canónigo o devoto contemporáneo ${ }^{28}$. También habría que considerar la posibilidad de una donante femenina, ya que el tema del "Juicio de Paris" resulta adecuado para decorar el joyero de una dama. A este respecto, hemos de tener en cuenta a varias mujeres de cierta cultura y de familia acomodada que residieron o mantuvieron estrechos vínculos con Alcalá entre la segunda mitad del XVI y finales del XVII. Podría ser el caso, entre otras varias, de María de Mendoza, hija de don Diego Hurtado de Mendoza y de doña Ana de la Cerda y Castro, y nieta del Gran Cardenal de España ${ }^{29}$. Doña María se había educado en las cortes española y francesa, fue amiga y musa del poeta y humanista Alvar Gómez de Castro, que le dedicó algunas de sus obras, y vivió en Alcalá entre 1562 y 1567 en una casa de la calle Santiago que, a su muerte, legó a los dominicos para fundar un convento ${ }^{30}$. Tampoco hemos de olvidar que doña Juana de Mendoza habitó en la casa de los Lizana, que dejó también a su muerte para fundar un convento de dominicas, y que fue enterrada en la iglesia Magistral en el año $1587^{31}$

En cuanto a la arqueta de la catedral de Palencia ${ }^{32}$, Fernández de Madrid afirmó que se trataba de un donativo de don Francisco Reinoso ${ }^{33}$. Castillo Olivares y Brasas Egido indicaron que la trajo de Roma este mismo canónigo palentino ${ }^{34}$. Este último historiador señaló en 1999 que se trataba de un primitivo joyero reconvertido en basamento para el relicario de San Antolín ${ }^{35}$. Sus relieves, se han interpretado de forma sucesiva como escenas de contenido eucarístico y como personificaciones de los Elementos (fig. 7) ${ }^{36}$.

La pieza se halla hoy bastante deteriorada, con la chapa de la cubierta perdida y con los cuatro ángulos recompuestos con trozos diversos, algunos encajados al revés por lo que varias figuras decorativas de desnudos infantiles aparecen boca abajo. Los dos relieves de cada uno de los

${ }^{27}$ Heredia Moreno, C., "Donaciones de plata labrada del cardenal arzobispo de Toledo don Bernardo de Sandoval y Rojas", en Estudios de platería. San Eloy 2003, Murcia, 2003, pp. 262-281.

28 Annales Complutenses, Alcalá de Henares, 1990, p. 633, edición de Carlos Sáez.

${ }^{29}$ Hidalgo Ogáyar, J., Los Mendoza y Alcalá de Henares. Su patronazgo durante los siglos XVI y XVII, Alcalá de Henares, 2002, pp. 25-26.

30 Alvar Ezquerra, A., Aproximación a la poesía latina de Alvar Gómez de Castro, Madrid, 1980, t. I, Gómez de Castro le dedicó el poema "Del origen y la orden de las vírgenes vestales" y en "Coralia". Por su parte, María donó a Alvar todos sus libros.

31 Hidalgo Ogáyar, J., Los Mendoza y Alcalá..., op. cit., pp. 17-22.

${ }^{32}$ Mide $80 \times 44,5 \times 33 \mathrm{~cm}$.

${ }^{33}$ FernÁndez de Madrid, A., Silva palentina, Palencia, 1977, p. 775, hace referencia al libro de Ascensio, fol. 99, v. ${ }^{\circ}$

${ }^{34}$ La dio a conocer y la reprodujo Castillo Olivares, A. del, "Orfebrería religiosa en Palencia (capital)", Publicaciones de la Institución "Tello Téllez Meneses", núm. 37, 1976, p. 134 y figs. 18-19. Brasas Egido, J. C., La platería palentina, Palencia, 1982, p. 73. También PARRAdo Del Olmo, J., "Evolución artística de la catedral de Palencia a través del gobierno de los obispos del Renacimiento (1512-1594)", en Jornadas sobre la ciudad de Palencia, Palencia, 1988, pp. 143-182 se hace eco de la donación de la arqueta "con temas renacentistas de procedencia italiana" y de otros regalos para la catedral como "dos candeleros y cruz de altar, palentinos, obras posibles de Gaspar Pinto. Los dos relicarios de San Antolín compuestos a partir de una copa alemana de Nuremberg pero traídos de Italia"

35 Brasas Egido, J. C., "Arqueta", en La platería en Castilla y León durante el reinado de los Austrias Mayores, Valladolid, 1999, p. 474-75, núm. 63 la documenta en los inventarios de alhajas de la catedral como "que sirve por peana a la imagen de S. Antolín, quando se pone en la cueba, diola el Sr. Obispo de Cordova...".

${ }^{36}$ La primera interpretación se debe a CASTILlo Olivares, A. del, "Orfebrería...", núm. 37, 1976, p. 134 y figs. 18-19. La segunda a J. C. BRASAS EgIDo, La platería palentina..., p. 73. En cualquier caso, frente a las ricas asas de las arquetas anteriores, la de Palencia presenta sencillas bolas de madera. 


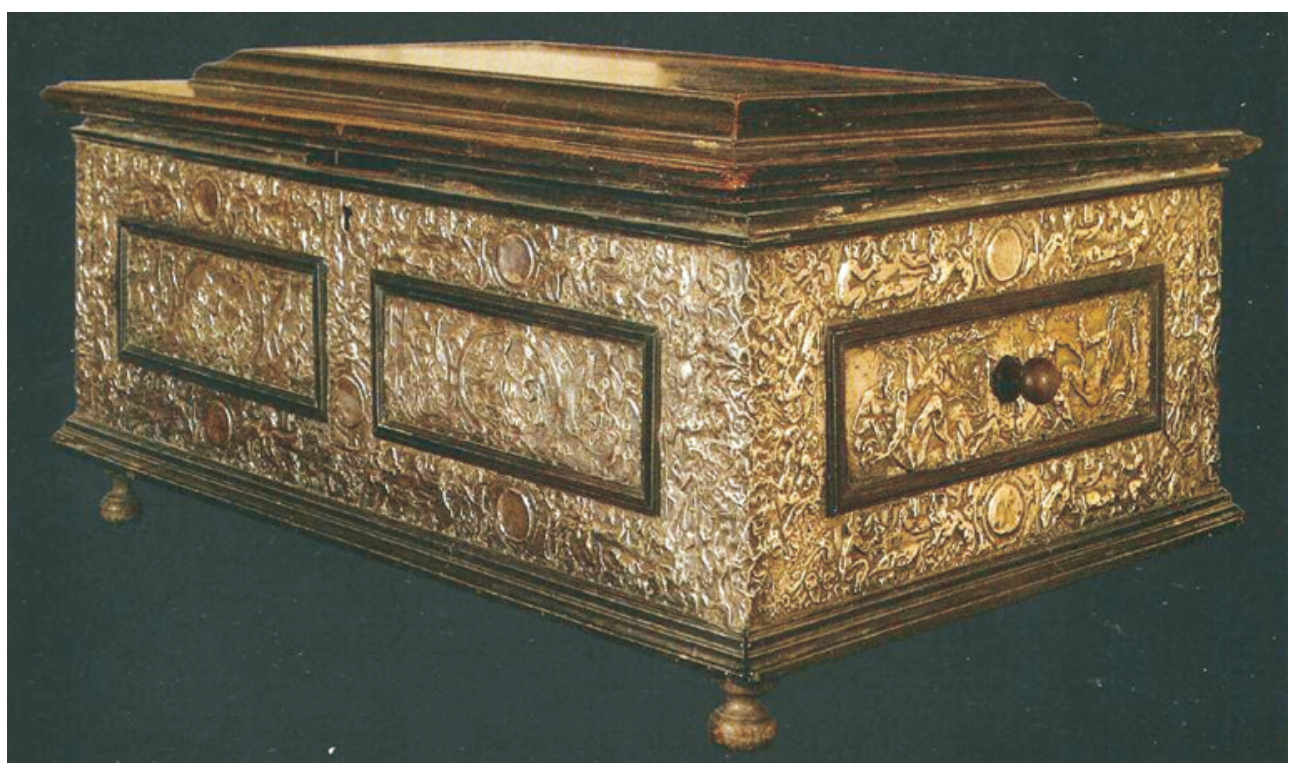

Fig. 7. Arqueta de la catedral de Palencia.

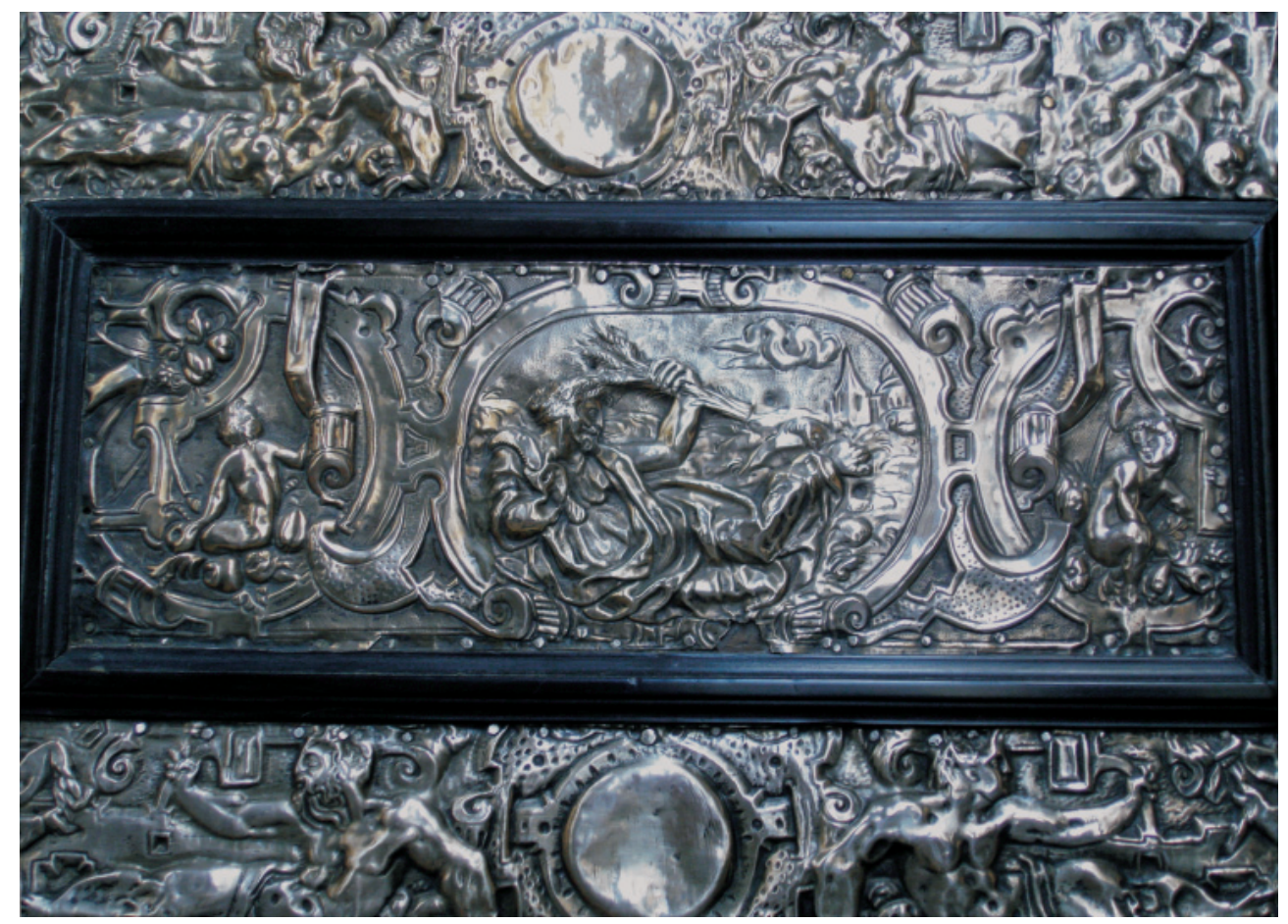

Fig. 8. Arqueta de la catedral de Palencia. La Tierra. 
dos frentes mayores repiten en el interior de cartelas de cueros sendas figuras masculinas recostadas sobre un fondo de paisaje, una con corona vegetal y un manojo de espigas, la otra con un recipiente con fuego ${ }^{37}$. En los frentes menores se repiten también dos parejas de desnudos en actitudes contrapuestas y con grandes vasijas de agua, posibles personificaciones de ríos y de ninfas. Por lo tanto, opinamos que el programa podría referirse a los elementos, como ya indicó Brasas. Si esto fuera cierto, los personajes con las espigas habría que relacionarlos con la Tierra que se representa, según Cesare Ripa siguiendo a Diógenes Laercio, "en la figura del Padre Dios, también llamado Plutón, es decir riquísimo rey y señor de la tierra toda, puesto que en ella reposan y se guardan los más preciosos tesoros..." (fig. 8). En cambio, según las mismas fuentes, la segunda figura sería Júpiter como personificación del Fuego ${ }^{38}$. El agua estaría representada por los ríos y las ninfas y, por último, el aire debería figurar en la cubierta.

No obstante, la pérdida de este último relieve y la repetición de los que hoy se conservan, dificultan la interpretación correcta y completa del programa, si es que el conjunto se concibió con un significado unitario y no como acumulación de simples elementos decorativos propios de la época. En cualquier caso, la traza general de la arqueta y el diseño de los desnudos se asemejan a los de las de Fuensalida y de la Magistral, aunque las sencillas patitas de madera y, sobre todo, las asas dan a la de Palencia un aspecto menos rico y más sobrio que al resto de los ejemplares.

Por lo que se refiere al donante, la trayectoria vital del prelado la conocemos por varias fuentes. Gregorio de Andrés nos informa que don Francisco fue el cuarto de los once hijos de los señores del lugar, don Jerónimo Reinoso y doña Juana de Baeza, había estudiado artes y teología en la universidad de Salamanca y en el año 1562 marchó a Roma al servicio del cardenal alejandrino Miguel Ghislieri, que le nombró "scalco secreto, cubicularius", camarero del secreto de Pío V y maestresala hasta la muerte del pontífice en 1572. Durante su estancia en la capital italiana entabló amistad con los embajadores don Francisco de Vargas y don Luis de Zúñiga y Requesens, comendador mayor de Castilla. Su regreso a España tuvo lugar en el año 1575 y Felipe II, en agradecimiento por la reliquia de San Lorenzo que había donado al monasterio de El Escorial, lo designó obispo de Córdoba en el 1597. En esta ciudad andaluza falleció cuatro años después y fue enterrado en la capilla mayor de su catedral a la que nombró heredera universal de todos sus bienes ${ }^{39}$. Estos hechos permiten apuntar la idea de que el agradecimiento del soberano se materializase también en el regalo de una arqueta de plata con figuras alegóricas, como las que hacía su platero Manuel Correa, que don Francisco Reinoso regaló después a la catedral de Palencia ${ }^{40}$. La idea parece atractiva y posible, pero no pasa de ser una mera hipótesis porque, desgraciadamente, carecemos de documentos que la confirmen.

En cualquier caso, los biógrafos de don Francisco han insistido en su munificencia. Por ejemplo, Gregorio de Andrés recuerda que antes de partir para su nueva diócesis "hizo algunos gastos muy excesivos y dio joyas de mucho valor, que había traído de Italia" y que "repartió con las

37 Para RiPA, C., Iconología, Madrid, 1985, las personificaciones del verano y del invierno son hombres por lo que los relieves de la arqueta no son del todo ortodoxos, pero hay que tener en cuenta que la arqueta de plata es anterior.

${ }^{8}$ C. RIPA, Iconología, Madrid, 1985, pp.311-312. Además, según Empédocles, los cuatro Elementos se combinan según las principales potencias amistad y discordia, una de las cuales reúne y la otra separa.

39 De Andrés, G., "Perfil artístico de don Francisco de Reinoso", Institución Tello Téllez Meneses núm. 67, 1996, pp. 91-120. Castro Sánchez, M. de, Vida de don Francisco Reinoso, Institución Tello Téllez Meneses, Palencia, 2001.

${ }^{40}$ Manuel Correa se encargó también de labrar algunos cálices limosneros como el que Felipe II donó al convento de San Juan de la Penitencia de Alcalá de Henares en el año 1571. Sobre estos cálices y sobre la trayectoria del platero, Cruz Valdovinos, J. M., "Manuel Correa, platero de Felipe II", El Arte en las Cortes..., op. cit., pp. 348-361. 
iglesias y conventos de Palencia muy ricas cosas. A la catedral dio un arca de plata y otras piezas que valían más de 700 ducados; a las demás dio cruces, candeleros, frontales, casullas, tablas de excelentes pintores y otras piezas ricas" ${ }^{\text {"41 }}$. De estas donaciones queda todavía una interesante copa civil, labrada en talleres de Nuremberg en la década de 1560, que don Francisco dividió a finales del siglo XVI en dos relicarios de San Antolín y que en los años ochenta del siglo XX fueron restituidos a su forma original en los talleres Granda ${ }^{42}$. Arias Martínez afirma también que el prelado acumuló prebendas y honores en la corte pontificia y que, tras su vuelta de Roma, vivió en Palencia como un gran señor rodeado de lujos ${ }^{43}$. No obstante, Castro Sánchez nos aclara que en el año 1591 vendió "las tapicerías y plata para dar limosna"44. Tales ventas deben ser la causa de que, según indica en su testamento, cuando fue a tomar posesión de su obispado, sus sobrinos, don Pedro de Reinoso y doña Inés Santoyo, tuvieran que prestarle diversas joyas y piezas de plata, entre las que se encontraban una cruz pectoral de oro con siete esmeraldas y cuatro perlas o varios platoncillos y dos fuentes con sus aguamaniles ${ }^{45}$.

Por último, en la reciente exposición sobre el patrimonio complutense, celebrada en la Real Academia de Bellas Artes de San Fernando en septiembre de 2008, se exhibió otra arqueta que se custodia en el arzobispado de Madrid desde fecha incierta (fig. 9) ${ }^{46}$. Se clasificó como obra castellana anónima del último tercio del XVI, con figuras femeninas echadas, posible representación de las Virtudes, sobre recuadros rectangulares donde "se vislumbran letras"47. Respecto a las fuentes iconográficas, se supuso que las hermas procedían de la decoración de la galería de Francisco I en Fontainebleau y que las figuras recordaban un dibujo para tazza de Etienne Delaune del Victoria and Albert Museum ${ }^{48}$.

Aunque nunca antes se había publicado, la existencia de esta última arqueta se conocía desde hacía tiempo y en el ámbito religioso madrileño y complutense se solía denominar "la arqueta de Cisneros" porque se creía que contuvo los restos mortales del prelado. Es decir, se confundía con la del monasterio de las Bernardas, lo cual no es correcto según hemos mostrado en páginas anteriores $^{49}$. La consulta de los documentos de la Junta de Incautación en la Guerra Civil y el análisis detenido de la obra proporciona algunas pistas sobre su posible procedencia y sobre su anterior destino.

En la mencionada acta de la Junta, que lleva fecha del 14 de marzo de 1937, se recogen tres arquetas de plata además de la de las Bernardas. La número 17 se identifica exactamente igual que la anterior, es decir, como una "arqueta con chapas repujadas y filetes de ébano, S. XVII (Santa María)". En el número 41 se anota una "pequeña arquilla de plata cincelada. Fines del XVIII" y en el número 95 figura otra "arqueta de plata repujada y cincelada, S. XVIII. Contiene varias piezas de vestido, un cetro, una placa, etc." ${ }^{150}$. Las descripciones

${ }^{41}$ ANDRÉs, G. de, "Perfil artístico...”, p. 101.

42 Brasas Egido, J. C., La platería palentina, 1982, pp. 72-73.

43 Arias Martínez, M., “Copón de Nuremberg”, en Las Edades del Hombre. Memorias y esplendores, Palencia, 1999, p. 196

44 Fernández Martín, L., Episcopables palentinos, p. 61.

45 ANDRÉs, G. de, "Perfil artístico...", p. 116.

${ }^{46}$ Mide $53 \times 26 \mathrm{~cm}$ de base y 37 de alto.

${ }^{47}$ MTCY, "Arqueta”, en Alcalá, una ciudad en la historia, Madrid, 2008, núm. 48.

48 Aunque no se indica, supongo que se refiere al dibujo a pluma y aguada con cuatro figuras de Virtudes reproducido por HaYward, J. F., Virtuoso Goldsmiths, 1540-1620, New York, 1976, en la fig. 114, pero no creo que el artífice de la arqueta llegase a conocer tal dibujo.

49 A este respecto me remito a la nota 8 y a la obra de Marchamalo Sánchez, A. y M. Marchamalo Main, El sepulcro del Cardenal..., pp. 239-241 y 254, apéndices XIV y XVII.

${ }^{50}$ Instituto de Patrimonio Cultural Español (IPCE), Leg. 33, Acta n. ${ }^{\circ}$, Junta de incautación y Protección del Patrimonio. 14 de marzo de 1937..., op. cit., núms. 17, 41 y 95. 


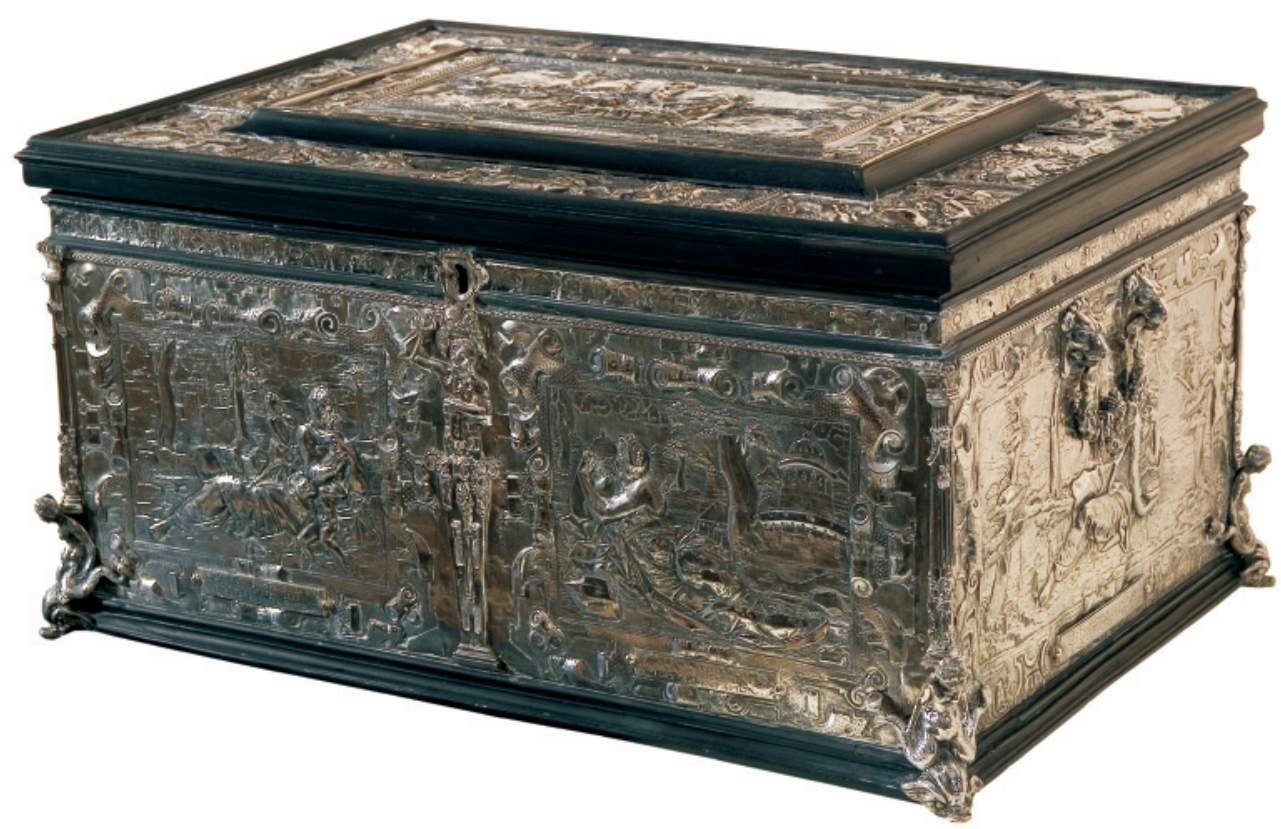

Fig. 9. Arqueta del Arzobispado de Madrid. Dirección General de Patrimonio. Comunidad de Madrid.

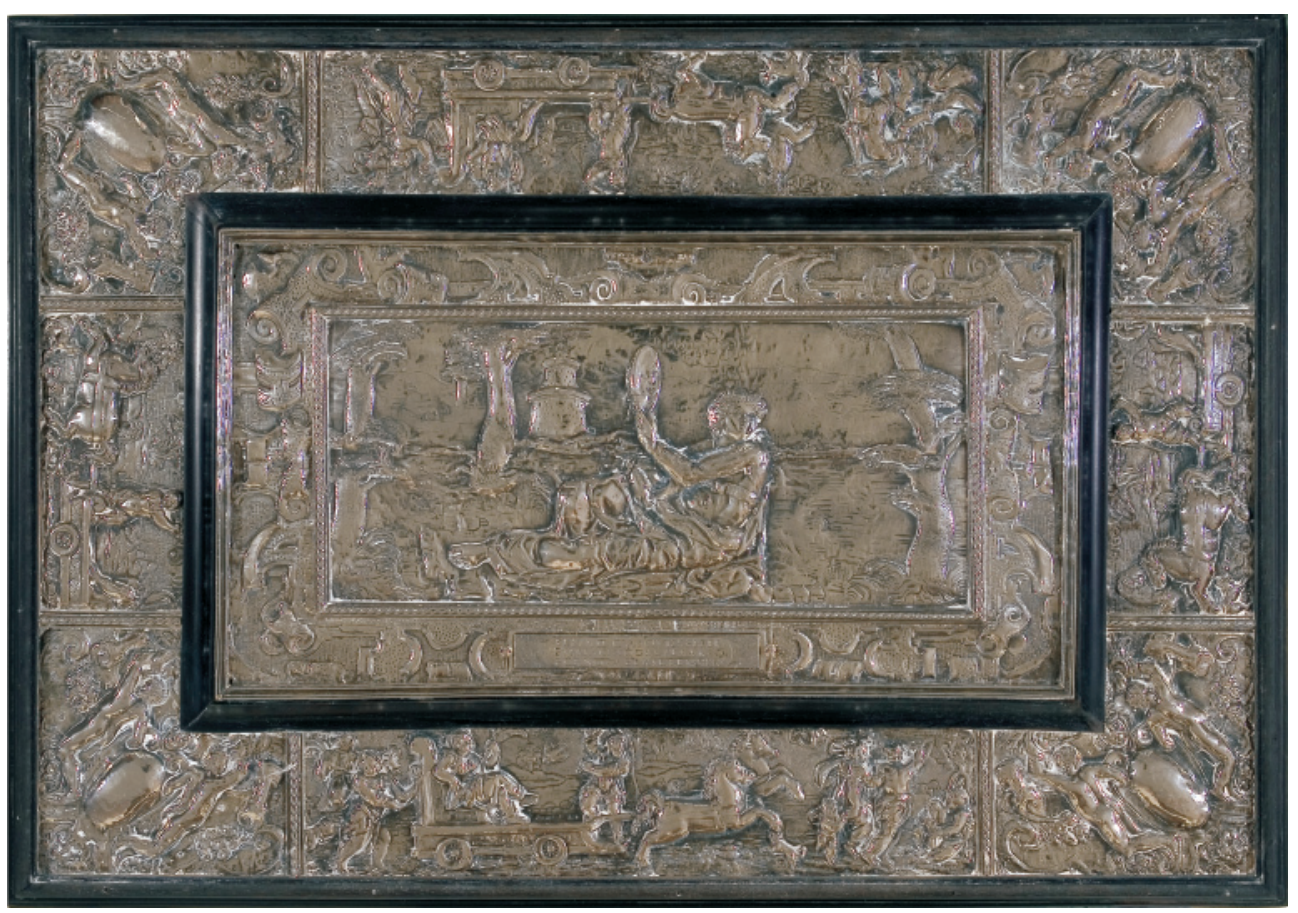

Fig. 10. Arqueta del Arzobispado de Madrid. La Templanza.

AEA, LXXXIII, 331, JULIO-SEPTIEMBRE 2010, 267-286, ISSN: 0004-0428 
resultan bastante vagas, pero si aceptamos que la pieza del Arzobispado madrileño perteneció realmente a la parroquia alcalaína y si tenemos en cuenta el parecido que tiene con la de las Bernardas (número 4) en su forma, materiales y frentes cubiertos de relieves figurativos, hemos de deducir que ambas se describirían de la misma manera y que, por lo tanto, la anotación que le corresponde debe ser la número 17, que repite las mismas palabras, incluso con la misma confusión de cronología, que la anterior. La 17 y la 95 fueron devueltas al ayuntamiento de Alcalá de Henares el 28 de febrero del año 1940, según consta en el acta correspondiente de devolución ${ }^{51}$. Sin embargo en la actual parroquia de Santa María hoy sólo se conserva la segunda, una interesante pieza del siglo XVII - no del XVIII- con la superficie dividida en recuadros geométricos cubiertos con chapas repujadas con temas vegetales, de probable factura complutense, según se ha dicho ${ }^{52}$ y según parece adivinarse por la impronta muy confusa de su posible marca de localidad. Por lo tanto, la arqueta del arzobispado tuvo que volver a Madrid entre 1940 y $1990^{53}$.

Igual que las anteriores, esta arqueta tiene planta rectangular, lados verticales y cubierta plana levemente escalonada en dos niveles. Toda su superficie se recubre con decoración cincelada, repujada y fundida, de muy buena factura, que, junto a los ricos materiales y a las acertadas proporciones, configuran una pieza suntuosa y de excelente calidad. Los cuatro ángulos se refuerzan con un orden de pilastras jónicas que apoyan en sirenas femeninas de doble cola sobre cabezas de delfines, mientras que en el centro de los dos frentes mayores se alzan sendos términos, mitad figuras humanas - masculino y femenino- y mitad estípites, que los dividen en dos superficies rectangulares. Llevan cartelas correiformes sujetando sus torsos desnudos, cruzan un brazo sobre el pecho y alzan el contrario para sostener cestillos con frutos y guirnaldas. En los costados laterales se ajustan las asas compuestas por enrollamientos de cartelas y mascarones que cuelgan de una barra horizontal sujeta entre las fauces de máscaras de león.

Otras cartelas enrolladas de gran tamaño sirven de marco a siete escenas figurativas que reproducen las personificaciones de las Virtudes Teologales y Cardinales en actitudes recostadas y sobre un fondo de paisaje con árboles frondosos y arquitecturas. Todas ellas se identifican por sus atributos y por sus respectivas inscripciones en tercetos octosílabos. A saber, la Templanza en la cubierta (fig. 10); la Justicia y la Prudencia, en los costados laterales (fig. 11); la Caridad

${ }^{51}$ Instituto de Patrimonio Cultural Español (IPCE), Actas de devolución de objetos incautados por la Junta, a Alcalá de Henares, en 28 de febrero de 1940. El núm. 69 dice "Arqueta de plata repujada y cincelada". S. XVIII (al ayuntamiento) y el núm. 73, "Arqueta de plata repujada y filetes de ébano" (al ayuntamiento). AHMAH, Hemos revisado también, sin éxito, los Libros de Actas del ayuntamiento de Alcalá para tratar de localizar alguna referencia sobre la posterior entrega del patrimonio mueble a sus respectivos propietarios complutenses. En cambio, en varias ocasiones se habla de la intención del cabildo de reconstruir la parroquia de Santa María, destruida a lo largo de la contienda, lo que permite sospechar que sus bienes se custodiaron en el consistorio durante varios años, al menos hasta 1947 en que ya se celebraron cultos en la antigua iglesia de los jesuitas reconvertida en parroquia de Santa María. De hecho, la entrega del 28 de febrero fue precedida de unos documentos dirigidos al Alcalde en los que se anuncia la inminente devolución y se insta a que "después de haberse reconocido por sus legítimos propietarios los objetos, se envíe relación a esta Comisaría de las personas o congregaciones a las cuales se entregan, ... debiendo preceder el envío de la referida nota, a la entrega a los propietarios". Se conservan algunas de estas notas (AHMAH, Leg. 1430/2 y 1430/3 y se dio el caso de alguna confusión, como la acaecida el28 de agosto de 1940 en que "Habiendo sido entregado por este Depósito del Museo Arqueológico a ese Ayuntamiento una escultura de Cristo Yacente propiedad de las RR MM Capuchinas de Madrid, se sirvan entregar a las RR. MM. portadoras del presente dicha escultura. Firmado Francisco Abbad".

${ }^{52}$ MTCY, “Arqueta”, en Alcalá, una ciudad..., op. cit., núm. 84.

${ }^{53}$ En 1990 se hizo el inventario de bienes muebles de la diócesis de Alcalá de Henares y, según las fichas que se conservan en el archivo del obispado, ya no figuraba en la parroquia de Santa María. 


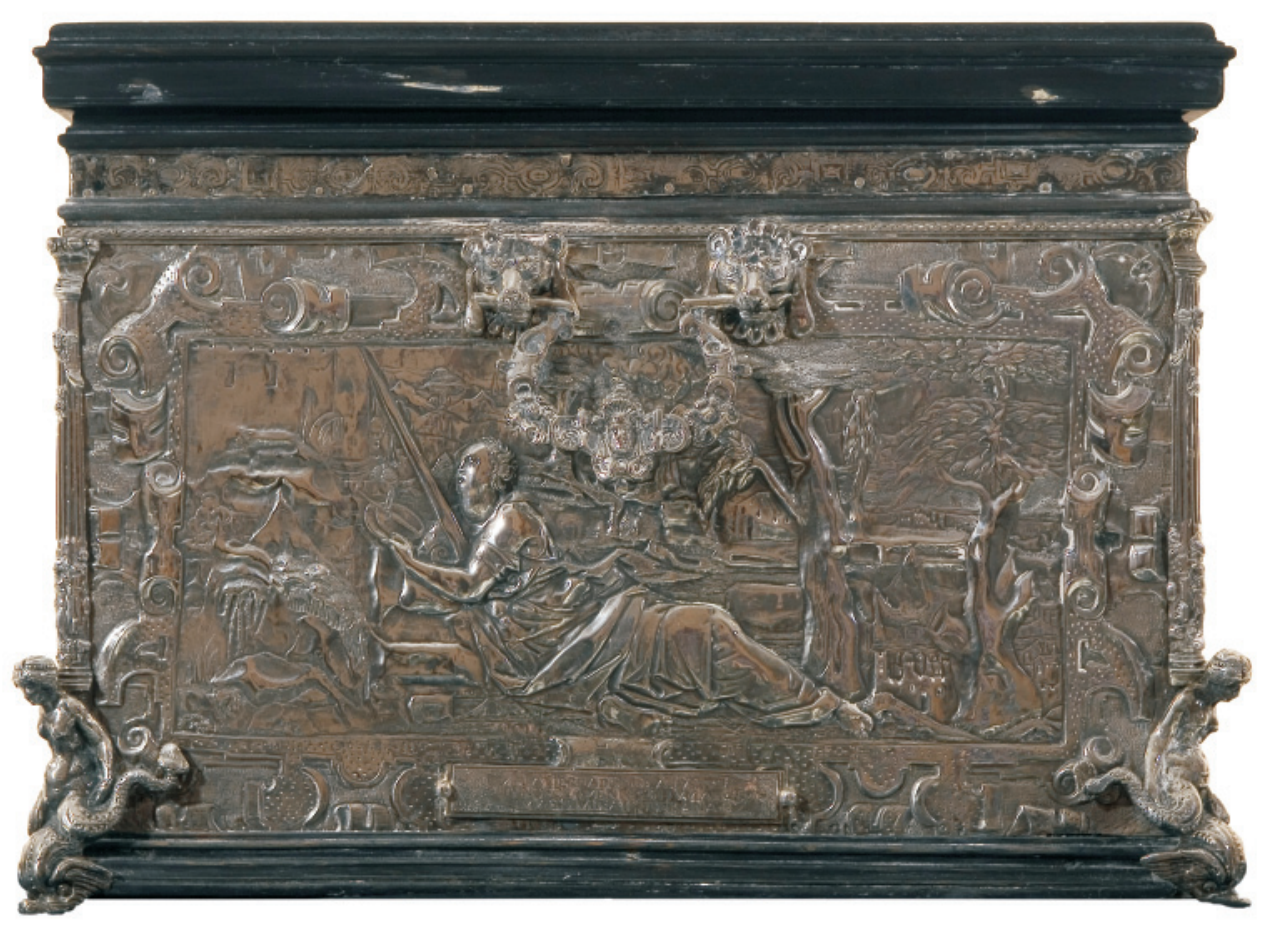

Fig. 11. Arqueta del Arzobispado de Madrid. La Justicia.

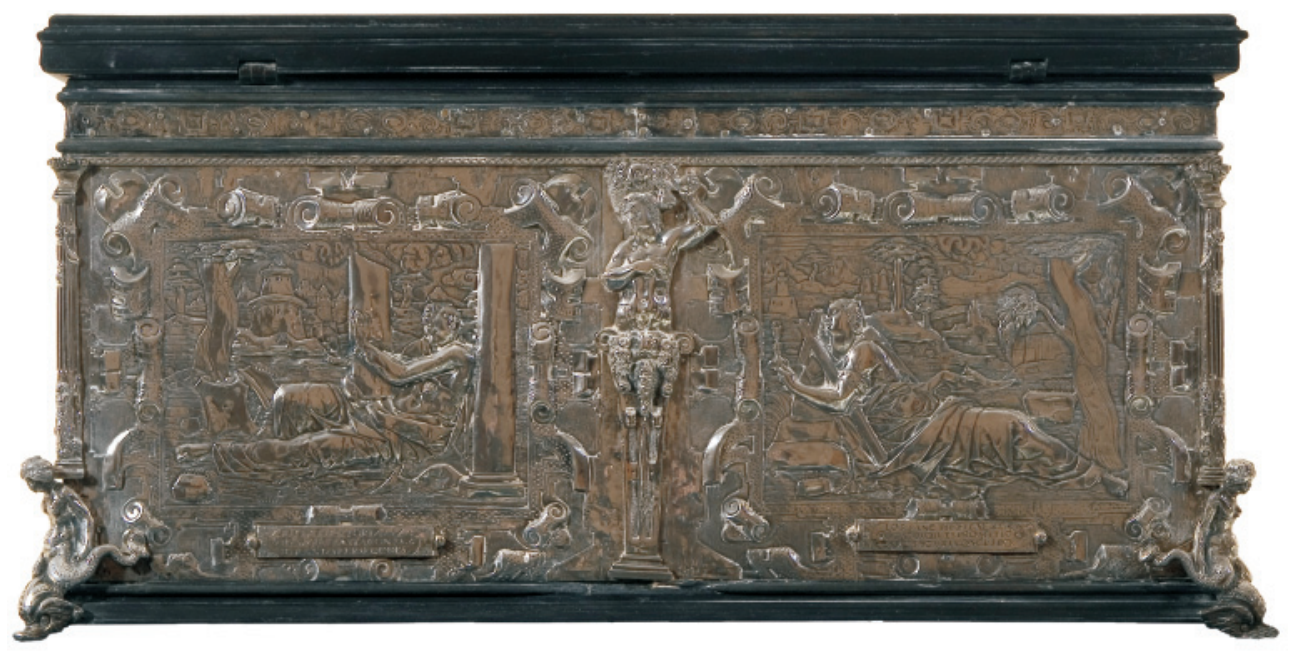

Fig. 12. Arqueta del Arzobispado de Madrid. La Fortaleza y la Fe. 
y la Esperanza (fig. 9), en el frente anterior, y la Fortaleza y la Fe, en el reverso (fig. 12) ${ }^{54}$. Sobre los ángulos de la plataforma inferior de la cubierta se reproducen gruesos óvalos entre parejas de niños desnudos espaldados, iguales a los de Palencia, y el resto de la superficie se decora con figuras sedentes sobre carros triunfales entre otros personajes, de difícil identificación y significado.

La procedencia del repertorio ornamental es diversa. Las sirenas de doble cola sobre delfines se localizan en estampas italianas de Perino del Vaga (c.1535-45) y del círculo de Francisco Salviati, del tercer cuarto del siglo XVI ${ }^{55}$. En España las utilizó el platero Francisco Merino en la arqueta de San Eugenio de la catedral de Toledo labrada en torno a 1565, según diseño de Nicolás de Vergara el Viejo, y se incorporaron también en la lámpara que la catedral primada contrató dos años después con los artífices Diego Cimbrón, Gonzalo Hernández y Marcos Hernández ${ }^{56}$. A su vez, este último artífice, que trabajó en el ámbito toledano-complutense, las introdujo en el enchufe del mango de su cruz parroquial de Valdeavero (1569-75). El platero de la arqueta añadió las grandes cabezas de delfines sobre las que cabalgan las sirenas. Por último, el alcalaíno Gaspar de Guzmán, discípulo de Marcos Hernández, bien porque las interpretó de manera equivocada, bien por su interés personal en crear nuevas formas, transformó las sirenas en arpías y conectó las dobles colas con las cabezas de los delfines en la custodia de El Casar de Talamanca (c. 1576) ${ }^{57}$. Con las manzanas de las cruces de Marcos Hernández -Valdeavero y Orgaz, por ejemplo-, se relacionan también los soportes jónicos de los ángulos, que apean sobre las sirenas y que muestran el tercio inferior del fuste decorado y el superior con telas y guirnaldas colgantes a la manera de la retablística toledana contemporánea ${ }^{58}$.

Los marcos de cartelas y los soportes de hermas estípites que centran los frentes mayores pertenecen al lenguaje común del repertorio manierista y se asemejan a los de los estucos ornamentales de la galería de Francisco I en Fontainebleau ${ }^{59}$. No obstante, puesto que el anónimo artífice de la arqueta no conoció personalmente la corte francesa, tuvo que valerse de alguna estampa, quizás de Antonio Fantuzzi que, entre 1537-40, había trabajado a las órdenes de Primaticcio y en la decoración de la Galería de Ulises del palacio francés ${ }^{60}$. También pudo manejar las series de cariátides y términos copiados de Agustino Veneciano, que se publicaron en 1536, ó, mejor aún, la serie de Vredeman de Vries, con alguna de cuyas parejas guarda bastante parentes-

${ }^{54}$ Inscripciones: "EL FIN DE CVALQVIER PLAZER/ ES PRINCIPIO DEL PESAR/ POR NO SABERSE TEMPLAR". "LA TIERRA DONDE AI JVSTICIA/ NO SOLAMENTE ES HVMANA/ MAS DIVINA I SOBERANA". "TAL VIRTVD HA LA PRVDENTIA/ QVE PERFECTAMENTE ELIGE/ I AL QVE ES VICIOSO CORIGE". "LOS SANTOS POR FE ALCANZARON/LO QVE DIOS LES PROMETIO/ QVES LA GLORIA QVE LES DIO”. “QVIEN TIENE ESPERANZA EN DIOS/ LIBRE ES DE TRIBVLACION/ I DE TODA TENTACION". "EL QVE TIENE FORTALEZA/ RESISTE LAS TENTACIONES/ I GRANDES PERSECVCIONES" y "LOS SANCTOS POR FE ALCANZARON LO QVE DIOS LES PROMETIO/ QVE ES LA GLORIA QVE LES DIO”.

55 Hayward, J. F., Virtuoso Goldsmith, figs. y 83.

56 Según Ramírez de Arellano, R., Estudio sobre la historia de la orfebrería toledana, Toledo, 1915, p. 79, fue Gonzalo Hernández, el hermano de Marcos, el que realizó "el vaso de en medio donde se pone el aceite, las cadenas y las sirenas (que las sujetan)".

57 Heredia Moreno, C. y A. López-Yarto Elizalde, "Una aproximación a la obra del platero Marcos Hernández y a sus fuentes iconográficas y decorativas", Cuadernos de Arte e Iconografia, t. VIII, núm. 16, 1999, p. 318, fig. 12 y La Edad de Oro de la platería complutense, Madrid, figs. 188-189 y 323.

58 Heredia Moreno, C. y A. López-Yarto Elizalde, “Una aproximación..., ob. cit. y La Edad de Oro..., p. 138. Los ángulos de la arqueta de las Bernardas también se refuerzan por pilastras y tanto en ésta como en la de Fuensalida las patas de madera se recubren con grandes volutas de plata.

${ }^{59}$ MTCY, "Arqueta", ob. cit.

${ }^{60}$ Berliner, R., Modelos ornamentales de los siglos XV al XVIII, Barcelona, s/f, p. 111. 
co aunque no las copia de forma literal ${ }^{61}$. Además, el modelo de asas de la arqueta madrileña se repite sustancialmente en las de Carlos V y de Fuensalida.

En cuanto a las representaciones figurativas, la presencia de las siete Virtudes permite suponer que, en este caso, la arqueta sí se labró con un destino religioso, quizás como contenedor de reliquias, aunque tampoco hay que descartar por completo que su uso primitivo fuese el de joyero o papelera y que el programa iconográfico se ideara para servir de espejo a su propietario al señalarle la práctica de las virtudes como camino de salvación. Al menos, las inscripciones refuerzan el significado de cada una de ellas y subrayan las consecuencias positivas que se derivarían de su ejercicio. De cualquier manera, las fuentes iconográficas de las Virtudes se localizan básicamente en la estampa de la Caridad del grabador flamenco Cornelis Cort, igual que en el ejemplar de las Bernardas ${ }^{62}$. Pero el platero la reinterpreta bajo tres variantes e incorpora en cada caso los atributos iconográficos adecuados ${ }^{63}$. La primera variante, que repite de manera literal el modelo femenino de Cort, se utiliza en la pieza de plata para las figuras de la Caridad, -excepto por la distinta colocación de los tres niños- y de la Prudencia, que sujeta una copa en cada mano ${ }^{64}$. El segundo modelo reproduce la misma imagen de la Caridad, pero invertida, y sirve para la representación de la $\mathrm{Fe}$-con cruz y cáliz-, la Justicia -con espada y balanza-, y la Esperanza, salvo pequeños detalles secundarios. Además, las tres primeras virtudes se repiten en los relieves homónimos de la arqueta de Las Bernardas. Un tercer modelo, semejante al primero pero con la pierna izquierda extendida y la derecha y la espalda dobladas en ángulo recto, siguen la Prudencia - con espejo entre las manos- y la Fortaleza - con columna y escudo-. La composición de estas dos últimas virtudes se acerca también a la estampa del olfato de la conocida serie de los sentidos de Frans Floris, cuyos dibujos de 1561 fueron grabados también por Cornelis Cort e impresos por Cock y se difundieron por toda Europa ${ }^{65}$.

Por lo que se refiere a las inscripciones, el contenido de los tercetos así como sus rimas y medidas resultan correctos, aunque su calidad poética no sea muy destacada. Pertenecen al género de versos que se utilizaban de forma habitual para recubrir las fachadas y las estructuras efímeras de la época o que competían en los certámenes poéticos que tenían lugar en los colegios y conventos universitarios con motivo de muchas fiestas públicas. Recordemos, por ejemplo, los cartones con poesías latinas y castellanas que adornaron la fachada de la Compañía de Jesús de Alcalá de Henares cuando entraron las reliquias de los Santos Niños Justo y Pastor en la villa en el año 1568, según el prolijo relato que nos dejó Ambrosio de Morales ${ }^{66}$.

61 The new Hollstein Dutch an Fleming etchings, engravings and woodcuts, Rotterdan, 1997, t. XLVII, pp. 206214, en especial las figuras 226, 228, 233 y 235. Parecida fuente de inspiración deben tener los grupos de hermas canéforas de los cántaros de óleos de la catedral de Sevilla procedentes de Amberes, tantas veces reproducidos.

${ }^{62}$ Está reproducida en The Illustrated Bartch, Cornelis Cort, 52, New York, 1986 y en Cornelis Cort, part II. The new Hollstein Dutch and Flemish etchings, engravings and woodcuts, Rotterdam, 2000, p. 140.

${ }^{63}$ El árbol de la cruz de Valdeavero ostenta también figuras de Virtudes recostadas dentro de óvalos que, pese a sus reducidas dimensiones, evidencian esquemas y actitudes semejantes a las de la arqueta.

${ }^{64}$ Reproducida, por ejemplo, en Cornelis Cort. The new Hollstein Dutch and Fleming etchings, engravings and woodcuts, ca. 1450-1700, Rotterdam, 2000, p. 240.

${ }^{65}$ KonËCny, A., Los cinco sentidos y el arte, Madrid, 1997, pp. 108-111. Estella Marcos, M., "Escultura y objetos de marfil, nácar y concha. 1. Arqueta de los cinco sentidos", en La catedral Magistral, Alcalá de Henares, Patrimonio de la Humanidad, Alcalá de Henares, 1999, pp. 157-165. La serie completa se utilizó en la arqueta de marfil de la Magistral.

${ }^{66}$ La vida, el martyrio, la invención, la grandeza y las translaciones de los gloriosos niños martyres san Justo y Pastor [...] en Alcalá, en casa de Andrés de Angulo, 1568. Lo comento y transcribe algunos versos ALASTRUÉ CAMPO, I., Alcalá de Henares y sus fiestas públicas (1503-1565), Alcalá de Henares, 1990, pp. 115-167. Esta autora recoge también algunos versos de las fiestas que tuvieron lugar en el año 1546 en honor del Cardenal Siliceo y de los festejos celebrados con motivo del matrimonio de Felipe II. Sobre éstos y otros festejos celebrados en Alcalá y Toledo pueden 
A tenor de lo dicho, parece evidente que la arqueta del arzobispado de Madrid se labró en algún obrador del arzobispado de Toledo. En el terreno de la hipótesis, un candidato idóneo podría ser, en primer lugar, el platero Marcos Hernández que conoció a Francisco Merino, trabajó para localidades próximas a Alcalá y con cierta frecuencia figura avecindado en la villa universitaria. En segundo lugar cabría considerar la autoría de su discípulo el complutense Gaspar de Guzmán. Las fechas de referencia para su realización estarían comprendidas entre 1565 y 1576, años en que se confeccionaron la arqueta de San Eugenio, la lámpara para san Dionis de París, las cruces de Valdeavero y de Orgaz o la custodia de El Casar de Talamanca y en los que las estampas que sirvieron de punto de partida ya se habían difundido por Europa y por España.

Por otra parte, las semejanzas entre las cinco arquetas que hemos analizado permiten aventurar que su factura tuvo lugar en unas fechas próximas y por mano de uno o varios artífices que trabajaron en el mismo ámbito geográfico. De hecho todas se labraron durante el reinado de Felipe II y algunas de ellas estuvieron en poder de personajes próximos al soberano. La del monasterio complutense de Las Bernardas la hemos atribuido al platero real Manuel Correa, que podría haber sido también el artífice de la de Palencia, sobre todo si consideramos que ésta última pudo ser un regalo del propio monarca a Francisco Reinoso. Además, Correa era de la misma generación que Francisco Merino y que Marcos Hernández, y es posible que los tres maestros conectasen en el entorno de la corte o de la catedral primada. Los contactos de Hernández con Merino en Toledo están documentados porque ambos tasaron los facistoles que Vergara el Viejo realizó para la catedral en 1574 y porque el primero fue también el tasador de las arquetas de San Eugenio y Santa Leocadia que había labrado el segundo ${ }^{67}$. Por último, el complutense Gaspar de Guzmán heredó muchos aspectos estilísticos de Marcos Hernández, como se demuestra al comparar sus obras. Todas estas conexiones permiten explicar muchos de sus rasgos comunes, así como la utilización de los mismos o parecidos motivos ornamentales y fuentes iconográficas comunes. Por lo tanto, no parece descabellado considerar que las arquetas de las Bernardas y de la catedral de Palencia se labrasen en torno a la corte madrileña de Felipe II por mano de algún platero real, como Manuel Correa, mientras que las de Fuensalida, Alcalá y Madrid se hubiesen realizado en el ámbito de la platería toledana o complutense contemporánea en el entorno de Marcos Hernández y de su círculo. El tema del Juicio de Paris y las inscripciones en tercetos constituyen otros detalles a tener en cuenta para relacionar las tres últimas piezas con el contexto cultural y con las fiestas públicas de la villa universitaria o de la ciudad de Toledo, así como con algunos de sus plateros más relevantes.

A tenor de lo dicho, descartamos la procedencia de Italia que, en su día, se le otorgó a las arquetas de Fuensalida y de Palencia, tanto porque sus caracteres apuntan a talleres cortesanos y toledanos-complutenses, según hemos mencionado, cuanto porque desconocemos ejemplos italianos semejantes que pudieran haber servido de referencia. Por otra parte, como anunciábamos al principio, estas arquetas debieron jugar un papel significativo entre el variado repertorio de objetos que componían los ajuares domésticos contemporáneos propios de las clases nobles, como uno más de los muchos signos que certificaban su rango y su nobleza de vida ${ }^{68}$. Debieron

consultarse también, entre otros autores, CORDERo DE CIRÍA, E., “Alvar Gómez de Castro y la introducción en España de la cultura emblemática sin Alciato", Boletín del Museo e Instituto Camón Aznar, LXXIII, 1998, pp. 59-99. GoNZÁLEZ RAmos, R., La Universidad de Alcalá de Henares y las Artes. El patronazgo artístico de un centro del saber. Siglos XVIXIX, Alcalá de Henares, 2007, capítulos V, VII y XI.

${ }^{67}$ Heredia Moreno, C. y A. López-Yarto Elizalde, "Una aproximación al platero Marcos Hernández ..., ob. cit.

${ }^{68}$ Heredia Moreno, C. "Lujo y refinamiento. La platería civil y corporativa”, en SÁnchez-Lafuente Gémar, R., Andalucía barroca. El fulgor de la plata, Córdoba, 2007, pp. 66-83. 
ser objetos suntuarios muy apreciados, idóneos para intercambiar regalos de acuerdo con las normas sociales al uso, pero también para donarlos a una institución religiosa. Sus relieves mitológicos no siempre resultaban adecuados para uso litúrgico, pero estas piezas se solían situar en los retablos o en los monumentos del Jueves Santo y quedaban a suficiente distancia de los fieles para que ciertos detalles "indecorosos" pasasen desapercibidos ante el brillo, suntuosidad y carga simbólica de los materiales que, a la vacilante luz de las velas, cobraban particular protagonismo e importancia ${ }^{69}$. En el peor de los casos, se procedía a distorsionar los desnudos con unos simples golpes de martillo.

En plena época de la Contrarreforma, cuando ya se había definido y difundido la doctrina de Trento y se estaban aplicando sus directrices sobre el culto a la Eucaristía y el culto a los santos y a las reliquias, nada mejor que ofrecer estas obras, hechas con metales nobles, para contribuir al esplendor de la liturgia, ya que su traza resultaba fácil de adaptar para transformarla en relicario o en arqueta eucarística. El propio monarca Felipe II había dado ejemplo al convertir la basílica del monasterio de El Escorial en un gran contenedor de reliquias y en centro neurálgico del culto a la Eucaristía ${ }^{70}$. Con estos precedentes, los relicarios, arquetas eucarísticas y sagrarios alcanzaron importancia progresiva y su número creció de manera considerable a partir de entonces. En la misma ciudad de Alcalá todavía se conservan algunas otras arquetas de procedencia diversa y de donación desconocida que responden a este espíritu.

La más exótica, aunque contemporánea de las anteriores, es la del Convento de San Juan de la Penitencia, interesante pieza de arte namban, de madera lacada con incrustaciones de madreperla y latón y con aplicaciones de metal y vidrio, recubierta de pinturas vegetales y animales propios de la fauna oriental (aves del paraíso, felinos, etc.) ${ }^{71}$. Su llegada al convento hay que relacionarla con el galeón de Manila y con el comercio de productos orientales de lujo que se puso de moda en el reinado de Felipe II.

Más próxima pero no menos interesante nos parece, por último, el arca eucarística del Convento de Carmelitas Descalzas del Corpus Christi de la misma localidad complutense ${ }^{72}$. Además de sus ricos y variados materiales -jaspe tallado sobre alma de madera, con molduras de bronce fundido y con cenefas de plata cincelada y repujada- se ha señalado la semejanza de su estructura con otros ejemplares del siglo XVIII que se conservan en la Hermandad del Refugio de Madrid (José Antonio de Zafra, 1733-42) y en Villa de Prado (Ramón García, 1786), así como su posible conexión con el dibujo de Sebastián Herrera Barnuevo para el baldaquino destinado a la urna de San Isidro en su capilla de la iglesia de San Andrés de Madrid.

En mi opinión, la mezcla de materiales y, sobre todo, la traza vertical, con los frentes cajeados y la decoración vegetal, aunque más simplificada, se asemeja al diseño de la arqueta eucarística de la catedral de Granada, atribuida a Alonso Cano que fue el que modificó la estructura de estas piezas inaugurando estos diseños verticales con ecos arquitectónicos para aproximarlos al formato de los sagrarios que habían adquirido particular protagonismo a partir de Trento $^{73}$. No olvidemos que Cano paso varios años en Madrid y en su segundo viaje a la corte (16571660) participó en la decoración de la capilla de San Diego en su convento franciscano de Al-

\footnotetext{
${ }^{69}$ Heredia Moreno, C. "De lo profano a lo sagrado...", op. cit.

70 Osten Sacken, C. von der, El Escorial. Estudio iconológico, Bilbao, 1984, sobre todo el capítulo 2.

71 La dio a conocer Castillo Oreja, M. A., Clausuras de Alcalá, Alcalá de Henares, 1986, p. 73. Un análisis más profundo y reciente en CASTIllo Oreja, "Arca eucarística”, en Alcalá. Una ciudad en la historia, Madrid, 2008, núm. 73.

${ }^{72}$ MTYCY, “Arca eucarística”, en Alcalá. Una ciudad..., núm. 85.

73 Rivas CARmona, J., "La significación de las artes decorativas, suntuarias y efímeras en las catedrales: los Monumentos de Semana Santa y sus arcas de plata", en Ramallo Asensio, G. (ed.), Las catedrales españolas. Del Barroco a los Historicismos, Murcia, 2003, p. 253.
} 
calá de Henares, para la que trazó el retablo y pintó los lienzos de San Antonio de Padua y de la Estigmatización de San Francisco, hoy en el Museo del Prado ${ }^{74}$. Si nuestra tesis es cierta, el sagrario de las carmelitas de Afuera sería el precedente inmediato del de Granada que Cano diseñó hacia el año 1665 y que fue labrado por Diego Cervantes Pacheco, el platero de la catedral andaluza ${ }^{75}$.

Fecha de recepción: 4-IX-2009

Fecha de aceptación: 12-XII-2009

74 Pérez SÁnchez, A. E., "Capilla de San Diego en el convento franciscano de Alcalá de Henares”, en Zurbarán, Madrid, 1988, 327-331.

75 Está reproducida en SÁnchez-Lafuente Gémar, R., "La Orfebrería”, en Gila Medina, L. (coord.), El libro de la catedral de Granada, Granada, 2005, p. 597. 